\title{
Patient Characteristics Associated with and Changes Over Time in Trust in Inpatient Physicians
}

J Gen Intern Med 37(1):266-8

DOI: $10.1007 / \mathrm{s} 11606-021-06649-0$

(C) Society of General Internal Medicine 2021

\section{INTRODUCTION}

Physicians have been considered one of the most trusted professions in the USA. However, recent reports suggest that trust in the medical profession has eroded. ${ }^{1,2}$ One potential contributor to declining trust is the breakdown of the doctorpatient relationship resulting from discontinuity of inpatient care, ${ }^{3,4}$ where patients do not see their primary care doctor when hospitalized. Additionally, patients from underrepresented groups are less likely to trust the medical profession due to a legacy of racism and bias ${ }^{5}$ that has resulted in recognized disparities in care. However, whether these factors affect patients' trust in their inpatient physician is not well described. The aim of this study was to test whether certain patient demographic or clinical factors are associated with patients' trust in their inpatient physician and examine changes in patient trust in their inpatient physician over time.

\section{METHODS}

From 2006 to 2018, adult general medicine inpatients were recruited into an ongoing study of hospital care. Consented patients were contacted by phone 30 days after discharge and asked: "During your hospitalization did you have confidence and trust in the doctors treating you?" Responses included (1) Yes, always; (2) Yes, Sometimes; and (3) No. A multivariable logistic regression (combining responses "Yes, always" and "Yes, sometimes") model was used to test whether patients' age, gender, race, insurance status, length of stay (LOS), Charlson Comorbidity Score (CCS), and year of admission (2006-2018) were associated with patient trust in their inpatient physician. Interaction variables between gender and race and gender and age were included in the model to test for differences across gender, race, and age, and their association with patient trust.

Received September 15, 2020

Accepted January 31, 2021

Published online February 25, 2021
RESULTS

From 2006 to $2018,76,265$ patients were eligible for study participation, 54,430 (71\%) consented to participate, and $37,116(68 \%)$ completed the follow-up survey. The mean patient age was 58, $21,779(59 \%)$ were female, and 26,777 $(72 \%)$ were African American (Table 1). Overall, 35,267 $(95 \%)$ expressed trust in their inpatient physician, and only $1849(5 \%)$ patients expressed no trust. In the regression model (Table 2), trust in their physician was associated with older age (age: 44-59 OR=1.2, $p<0.01,60-74 \mathrm{OR}=1.6, p=<0.01, \geq 75$ $\mathrm{OR}=1.6, p=<0.01)$, and having private insurance $(\mathrm{OR}=1.2$, $p<0.01$ ). Females (OR $0.63, p<0.01$ ) were less likely to trust

Table 1 Patient Characteristics

\begin{tabular}{|c|c|}
\hline \multicolumn{2}{|l|}{$n=37,116$} \\
\hline Age, mean $\pm \mathrm{SD}$ & $58 \pm 19$ \\
\hline \multicolumn{2}{|l|}{ Age quartiles, $n(\%)$} \\
\hline $18-44$ & $8833(24)$ \\
\hline $45-59$ & $9637(26)$ \\
\hline $60-74$ & $10,776(29)$ \\
\hline $75+$ & $7870(21)$ \\
\hline Female, $n(\%)$ & $21,779(59)$ \\
\hline \multicolumn{2}{|l|}{ Race, $n(\%)$} \\
\hline White & $7771(21)$ \\
\hline Black or African American & $26,777(72)$ \\
\hline Other & $1648^{4}$ \\
\hline Unknown/refused & $920(3)$ \\
\hline \multicolumn{2}{|l|}{ Insurance status, $n(\%)$} \\
\hline Private & $7837(21 \%)$ \\
\hline Medicare & $19,116(52 \%)$ \\
\hline Medicaid & $9405(25 \%)$ \\
\hline Uninsured & $758(2 \%)$ \\
\hline \multicolumn{2}{|l|}{ Length of stay (days), $n(\%)$} \\
\hline 1 & 6984 (19) \\
\hline $2-3$ & $7592(20)$ \\
\hline $3-5$ & $9754(27)$ \\
\hline $5-7$ & $4988(13)$ \\
\hline$\geq 7$ & $7798(21)$ \\
\hline \multicolumn{2}{|c|}{ Charlson Comorbidity Index, $n(\%)$} \\
\hline 0 & $11,735(32 \%)$ \\
\hline $1-2$ & $15,180(41 \%)$ \\
\hline $3-4$ & $7425(20 \%)$ \\
\hline 5 & $2776(7 \%)$ \\
\hline \multicolumn{2}{|l|}{ Admission year, $n(\%)$} \\
\hline 2006 & $2894(8)$ \\
\hline 2007 & $1787^{5}$ \\
\hline 2008 & $1366^{4}$ \\
\hline 2009 & $1065^{3}$ \\
\hline 2010 & $1154^{3}$ \\
\hline 2011 & $2399^{6}$ \\
\hline 2012 & $2893(8)$ \\
\hline 2013 & $3523(9)$ \\
\hline 2014 & $3936(11)$ \\
\hline 2015 & $3807(10)$ \\
\hline 2016 & $3999(11)$ \\
\hline 2017 & 4977 (13) \\
\hline 2018 & $3316(9)$ \\
\hline
\end{tabular}


Table 2 Trust in Inpatient Physicians by Patient Characteristics and Admission Year

\begin{tabular}{|c|c|c|c|}
\hline$n=37,116$ & $\begin{array}{l}\text { Odds } \\
\text { ratio }\end{array}$ & $95 \% \mathrm{CI}$ & $p$ value \\
\hline \multicolumn{4}{|l|}{ Age } \\
\hline $18-44$ & & Referent & \\
\hline $45-59$ & 1.2 & $1.1-1.4$ & $<0.01$ \\
\hline $60-74$ & 1.6 & $1.4-1.8$ & $<0.01$ \\
\hline $75+$ & 1.6 & $1.3-1.9$ & $<0.01$ \\
\hline Female & 0.63 & $0.51-0.78$ & $<0.01$ \\
\hline \multicolumn{4}{|l|}{ Race } \\
\hline White & & Referent & \\
\hline Black or African American & 0.88 & $0.72-1.1$ & 0.19 \\
\hline Other & 0.73 & $0.51-1.0$ & 0.07 \\
\hline Unknown/refused & 0.71 & $0.47-1.1$ & 0.13 \\
\hline \multicolumn{4}{|l|}{ Gender $x$ race $*^{\dagger}$} \\
\hline Black or African American Female & 1.5 & $1.2-1.9$ & $<0.01$ \\
\hline Other female & 1.6 & $0.99-2.6$ & 0.05 \\
\hline Unknown/refused female & 1.8 & $0.99-3.4$ & 0.05 \\
\hline \multicolumn{4}{|l|}{ Insurance status } \\
\hline Medicare & & Referent & \\
\hline Medicaid & 1.1 & $0.96-1.2$ & 0.18 \\
\hline Private & 1.2 & $1.1-1.4$ & $<0.01$ \\
\hline Uninsured & 1.3 & $0.89-1.8$ & 0.17 \\
\hline \multicolumn{4}{|l|}{ Length of stay (days) } \\
\hline 1 & & Referent & \\
\hline 2 & 1.0 & $0.89-1.2$ & 0.66 \\
\hline $3-4$ & 1.0 & $0.89-1.2$ & 0.83 \\
\hline $5-6$ & 1.0 & $0.87-1.2$ & 0.71 \\
\hline$\geq 7$ & 0.94 & $0.81-1.1$ & 0.43 \\
\hline \multicolumn{4}{|l|}{$\bar{C}$ Charlson Comorbidity Index } \\
\hline 0 & & Referent & \\
\hline $1-2$ & 0.94 & $0.84-1.0$ & 0.26 \\
\hline $3-4$ & 0.96 & $0.83-1.1$ & 0.56 \\
\hline 5 & 1.1 & $0.87-1.3$ & 0.50 \\
\hline \multicolumn{4}{|l|}{ Admission year } \\
\hline 2006 & 1.0 & $0.82-1.3$ & 0.75 \\
\hline 2007 & 1.1 & $0.86-1.5$ & 0.39 \\
\hline 2008 & 1.0 & $0.77-1.4$ & 0.82 \\
\hline 2009 & 1.0 & $0.74-1.4$ & 0.97 \\
\hline 2010 & 0.97 & $0.72-1.3$ & 0.87 \\
\hline 2011 & 1.0 & $0.80-1.3$ & 0.91 \\
\hline 2012 & & Referent & \\
\hline 2013 & 1.3 & $1.0-1.6$ & 0.03 \\
\hline 2014 & 1.1 & $0.90-1.4$ & 0.30 \\
\hline 2015 & 0.84 & $0.68-1.0$ & 0.10 \\
\hline 2016 & 1.1 & $0.90-1.4$ & 0.28 \\
\hline 2017 & 1.1 & $0.88-1.3$ & 0.43 \\
\hline 2018 & 1.4 & $1.1-1.8$ & $<0.01$ \\
\hline
\end{tabular}

* Referent categories are male gender and white race

Interaction effect overall $p$ value $<0.01$

their physician. There was a significant interaction between gender and race, with females identifying as African American (OR 1.5, $p<0.01$ ), other (OR 1.6, $p<0.01$ ), or unknown/refused (OR $1.8, p<0.01)$ race, reporting greater trust in their physician than white females. There was no association between patient trust in their physician and LOS or CCS. There was no association between patient trust in their physician and the year of admission besides $2013(\mathrm{OR}=1.3, p=0.03)$ and 2018 $(\mathrm{OR}=1.4, p<0.01)$ (Fig. 1), where small increases in trust were observed. Controlling for hospitalist service vs non-hospitalist did not change the results.

\section{DISCUSSION}

The overwhelming majority of patients reported trust in their inpatient physician. Despite significant changes to inpatient care delivery over the study period including the growth of hospitalists, there were no sustained changes in trust. However, some patient characteristics (age, gender, race, insurance status) were associated with increased trust in their inpatient doctor. Older adults may report greater trust due to increased familiarity with hospital care and represent a generation that has historically trusted physicians more than younger adults today. Privately insured patients may trust their inpatient physicians more due to greater access and fewer financial concerns regarding their care. ${ }^{6}$ Females may be less trusting of their inpatient physician than males as a result of gender inequity in healthcare or because they have stronger relationships with their primary doctors than men do. Why non-white females were more likely to trust their inpatient physician compared to white females is a finding that is inconsistent with past research and merits further exploration. 


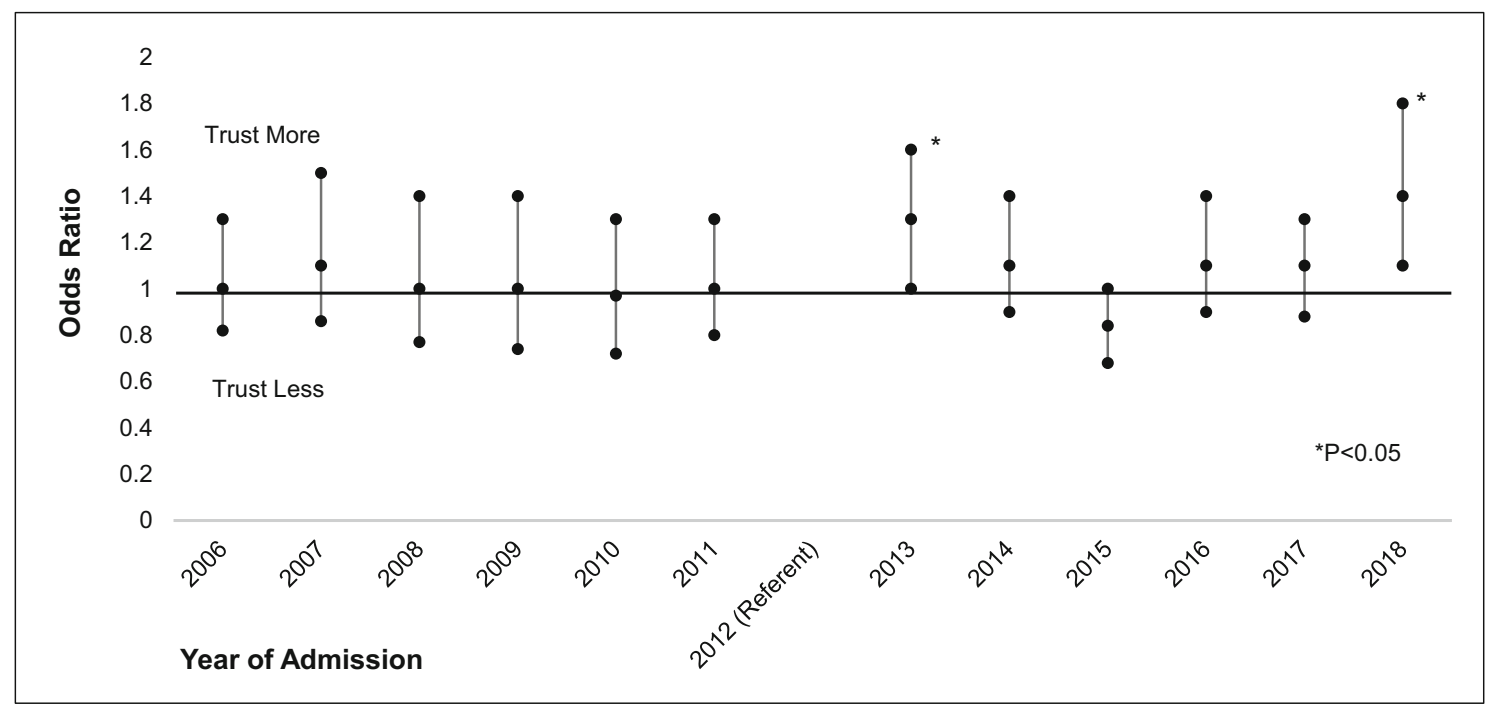

Fig. 1 Patient's Trust in Their Inpatient Physician Over Time

As a single-institution study, our results may not be generalizable. However, lessons from our experience may be salient. For example, the increases in trust in 2013 and 2018 correspond to institutional expansions in access to care (new hospital, opening trauma center), suggesting that health system investments can improve patient trust. Future work should focus on how to improve and capitalize upon trust in inpatient physicians, especially for diverse patients in multicenter prospective studies.

Acknowledgements: All authors that have contributed to this work are listed as authors of this manuscript and we have no additional acknowledgements.

Micah T. Prochaska, MD, MSc ${ }^{1}$

Hui Zhang, $P h D^{2}$

David O. Meltzer, MD, $P h D^{1}$

Vineet M. Arora, MD, MAPP

${ }^{1}$ Department of Medicine, The University of Chicago, Chicago, IL, USA

${ }^{2}$ Center for Health and The Social Sciences, The University of Chicago,

Chicago, IL, USA

Corresponding Author: Micah T. Prochaska, MD, MSc; Department of Medicine, The University of Chicago, Chicago, IL, USA (e-mail: mprochas@medicine.bsd.uchicago.edu).

Author's Contribution All authors have contributed to the development of this manuscript, including developing the idea, data analysis, writing, and revision.
Funding Dr. Prochaska is supported by a National Heart, Lung, and Blood Institute K23 Patient-Oriented Research Career Development Award. (NIH/NHLBI 1K23HL140132).

Dr. Meltzer is supported by a National Institutes of Health Clinical and Translational Science Award (NIH/NCATS UL1TR0002389).

Dr. Arora is supported by a National Heart, Lung, and Blood Institute K24 Midcareer Development Award (K24HL136859) and by a National Institute for General Medical Sciences UO1 Award (GM132375).

\section{Declarations:}

Conflict of Interest: The authors declare that they do not have a conflict of interest.

\section{REFERENCES}

1. Lynch TJ, Wolfson DB, Baron RJ. A trust initiative in health care: why and why now? Acad Med. 2019;94(4):463-5.

2. Blendon RJ, Benson JM, Hero Jo. Public trust in physicians-U.S. medicine in international perspective. N Engl J Med. 2014;371(17):1570-2.

3. Lo B. Ethical and policy implications of hospitalist systems. Am J Med. 2001;111(9B):48-52.

4. Rosenbloom AH, Jotkowitz A. The ethics of the hospitalist model. J Hosp Med. 2010;5(3):183-8.

5. Jacobs EA, Rolle I, Ferrans CE, Whitaker EE, Warnecke RB. Understanding African Americans' views of the trustworthiness of physicians. J Gen Intern Med. 2006;21(6):642-7.

6. Lo B. Serving two masters-conflicts of interest in academic medicine. N Engl J Med. 2010;362(8):669-71.

Publisher's Note Springer Nature remains neutral with regard to jurisdictional claims in published maps and institutional affiliations. 